\title{
Commingled Yarn Spinning for Thermoplastic/Glass Fiber Composites
}

\author{
Niclas Wiegand and Edith Mäder * \\ Leibniz-Institut für Polymerforschung Dresden e.V., Dresden D-01069, Germany; wiegand@ipfdd.de \\ * Correspondence: emaeder@ipfdd.de; Tel.: +49-351-465-8305 \\ Academic Editor: Stephen C. Bondy \\ Received: 25 April 2017; Accepted: 17 July 2017; Published: 20 July 2017
}

\begin{abstract}
Online commingled yarns were spun with three different polymeric matrices, namely polypropylene (PP), polyamide (PA) and polylactic acid (PLA) and glass fibers. Tailored sizings were applied for the three matrices and the resulting mechanical performance of unidirectional composites was evaluated and compared. Significant improvements in the fiber/matrix bonding were achieved by employed sizing chemistry in order to achieve multifunctional interphases. The pure silane coupling agents provide the best performance for all matrices investigated. However, an additional film former has to be added in order to achieve fiber processing. Film formers compatible to the matrices investigated were adapted. The consolidation behavior during isothermal molding was investigated for polypropylene matrix. Different fiber volume contents could be realized and the resulting mechanical properties were tested.
\end{abstract}

Keywords: commingled yarns; Polypropylene; Polyamide; Polylactic Acid; sizing; glass fibers; thermoplastic composites; multifunctional interphase

\section{Introduction}

Thermoplastic polymer matrices enable to manufacture composites at very short cycle times which makes them feasible for high volume productions. In contrast to thermosetting composites, they exhibit better impact resistance, higher toughness, recyclability and in the case of polylactic acid (PLA), even biodegradability. However, fiber impregnation is more difficult due to the high melt viscosity of the thermoplastic matrix. Different impregnation techniques have been proposed and performed. One of the most promising routines is provided by online commingled yarns which are based on the principle of homogeneous distribution of continuous matrix filaments and reinforcement glass filaments (GFs) during melt spinning [1]. This technique is more advantageous compared with air jet texturing because fibers were not damaged during commingling. The homogeneous fiber/matrix distribution of online commingled yarns especially leads to short impregnation paths and low void contents reflected by the high mechanical performance of the thermoplastic composites.

Besides our previous and main focus on polypropylene (PP)-glass fiber composite development and characterization [1-5] as well as highlighting the importance of the role of film formers [2] for both properties of fibers, processing and performance of composites, industrial demands for technical thermoplastics and higher temperature stability are increasing for structural components to be designed for mechanical engineering. One objective of our work is to enhance the thermal stability by introducing polyamide (PA) which also leads to higher strength and stiffness of continuous fiber reinforced thermoplastics. Therefore, the innovative approach of online commingled yarns consisting of PA and GF was carried out by using our unique and multi-tasking pilot plant.

On the other hand, biodegradable polymers like PLA have often been used in special non-load-bearing biomedical applications like tissue engineering or targeted release of active 
ingredients. In order to use PLA in orthopedics for bone fixation, it can be spun as online hybrid yarn with silica-based bioglass filaments to achieve the required high tensile strength and stiffness [6]. For this purpose, it is necessary to improve the adhesion strength between PLA and glass fiber to reach the properties of bone and to tailor the degradation behavior upon healing. An appropriately modified sizing can be used in order to reach these encountering challenges and being biocompatible.

Interphases in fiber-reinforced composites are vital regions for the stress transfer between fibers and matrices [7-10]. Implementing a percolated carbon nanotube (CNT) network into composite interphases allows the detection of mechanical stress-strain behavior by monitoring electrical response [3-5,11-17] and contributes to additional effects besides silane coupling agents and polymeric film formers. The change in electrical resistance gives a quantitative parameter for the deformation as well as the early stage damage formation in highly strained regions of the interphase [5], as shown in our previous work with online commingled yarns.

The objective of this work is to investigate the opportunities of the pilot plant to manufacture online commingled yarns with different polymeric matrices. As a comparison, PP, PLA and PA66 were spun together with GF. Besides the polymer matrix material aspects, the sizings, especially the influence of the different components within the sizing, will be discussed in terms of mechanical properties of GF composites. Online commingled yarns with different fiber volume contents will be spun and the effects on the mechanical properties of the composites are investigated. Another important topic is to investigate the consolidation parameters during isothermal compression molding in order to reduce the void content, thus increasing mechanical performance.

Here we will perform tensile and compression shear tests in order to determine the interphase effects due to sizings, compatible to different thermoplastic matrices.

\section{Experimental}

\subsection{Processing of Online Commingled Yarns and Interphase Modification}

The processing of online commingled yarns differs significantly from other commingling techniques. Glass and polymer filaments are simultaneously spun and commingled while passing the sizing applicator (Figure 1). This approach combines different advantages towards traditional commingling techniques, such as air texturing: the filament distribution homogeneity is reasonably high since commingling is done at a state where both matrix and glass fiber yarns do not possess pronounced fiber integrity. The online commingled yarn integrity is performed simultaneously with applying a sizing on the sizing applicator roll. The mechanical load on the yarn during commingling is negligibly low as compared to air jet texturing. Neither glass fibers are broken nor polymer fibers are stretched which results in high yarn strength and avoids thermal shrinkage during consolidation.

Depending on the matrix polymer, different sizings were applied during the fiber spinning, as shown in Table 1. All sizings consisted of a silane coupling agent and at least one polymeric film former. In order to investigate GF/matrix adhesion strength, silane and polymeric film former were systematically changed.

In this study, two different types of GFs were used during commingled yarn spinning at the Leibniz-Institut für Polymerforschung (IPF). For the preparation of structural composites, E-glass fibers with an average diameter of $17 \mu \mathrm{m}$ were continuously spun and sized with aqueous solutions. As matrix material for the commingled yarn spinning, PP and PA6.6 (HG455 FB, Borealis and Ultramid A27, BASF, Ludwigshafen, Germany) were used. For the preparation of the biomedical composites, silica-based bioglass fibers, having the same diameter as the E-glass fibers, were online commingled with PLA fibers (Ingeo 2002D, NatureWorks LLC, Minnetonka, MN, USA). In-situ commingled yarns consisting of 204 glass and 102 polymer filaments, respectively, were always spun. 


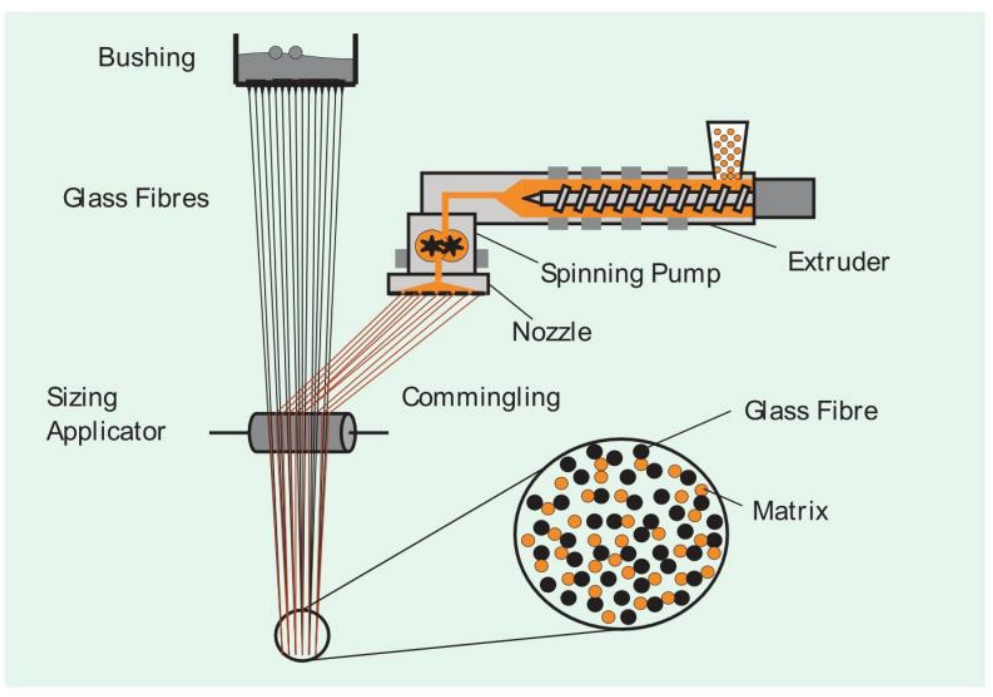

Figure 1. Principle of online hybrid yarn spinning.

Table 1. Sizing formulations applied during the hybrid yarn processing and glass filament (GF) volume fractions of manufactured composites.

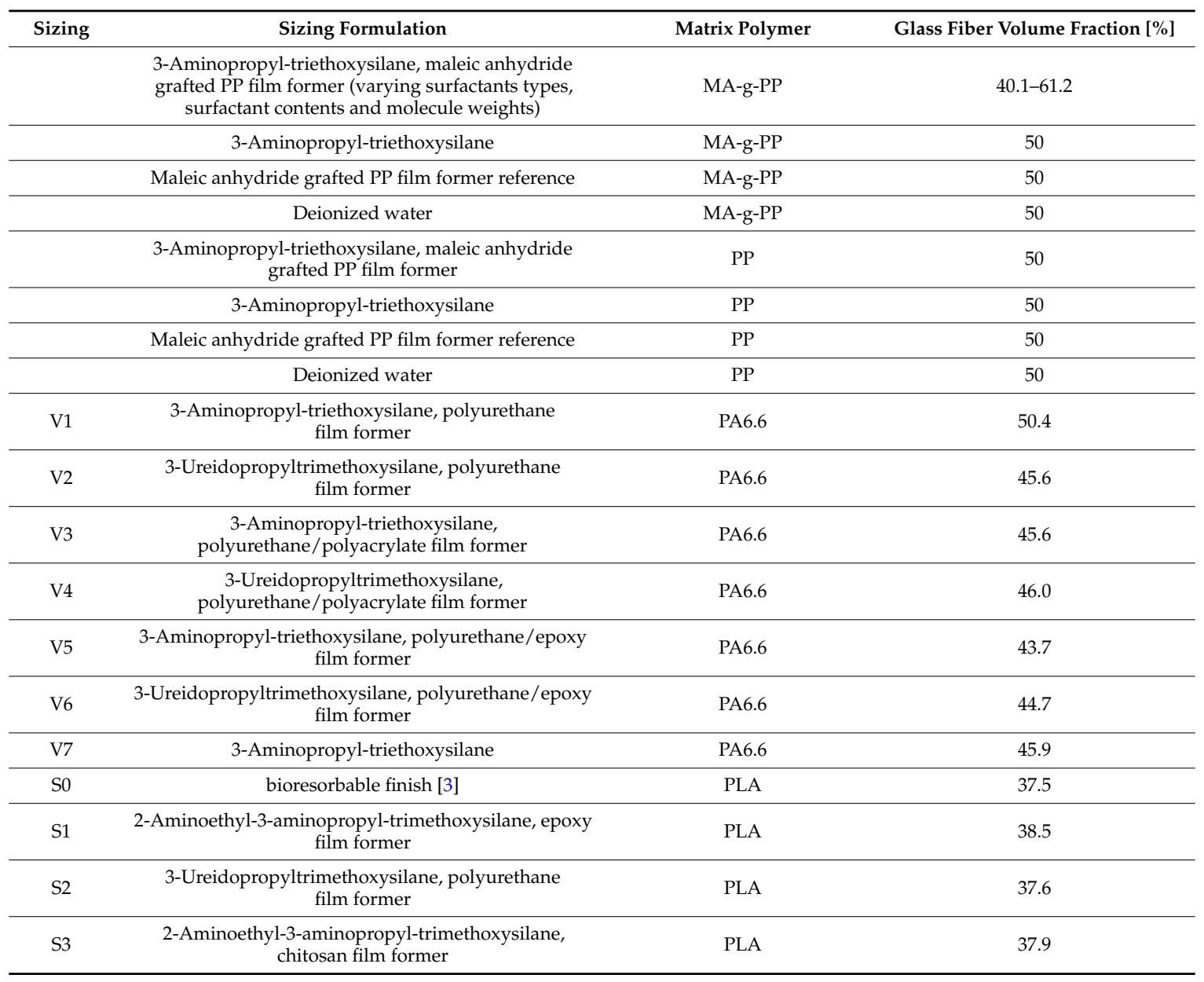

\subsection{Composite Manufacturing}

Unidirectional thermoplastic/glass fiber composites were produced using dry filament winding (IWT Wickeltechnik, Erlangen, Germany) of the commingled yarns followed by isothermal 
compression molding. In detail, commingled yarns were wound onto a mandrel until it was covered to the desired specimen thickness (1,2 and $4 \mathrm{~mm}$, depending on mechanical testing standards). After filament winding, the mandrels were transferred to a personal computer (PC)-controlled platen press (KV207, Rucks, Germany) for the consolidation process. Each mandrel was heated up from room temperature to isothermal temperature at a constant rate of $10 \mathrm{~K} / \mathrm{min}$ and a pressure of $0.43 \mathrm{MPa}$. After reaching the temperature, pressure was maintained along the defined consolidation time followed by a pressure increase up to the consolidation pressure and kept constant for $2 \mathrm{~min}$. Afterwards, the mandrels were cooled down to room temperature at $50 \mathrm{~K} / \mathrm{min}$ while maintaining the consolidation pressure. As a standard program, the following parameters shown in the Table 2 were used.

Table 2. Parameters for composite manufacturing.

\begin{tabular}{cccc}
\hline Matrix Polymer & $\begin{array}{c}\text { Isothermal Temperature } \\
{\left[{ }^{\circ} \mathbf{C}\right]}\end{array}$ & $\begin{array}{c}\text { Consolidation Time } \\
{[\text { min] }}\end{array}$ & $\begin{array}{c}\text { Consolidation Pressure } \\
{[\mathbf{M P a}]}\end{array}$ \\
\hline PP & 225 & 21 & 2.25 \\
PA6.6 & 295 & 20 & 2.25 \\
PLA & 170 & 20 & 1.5 \\
\hline
\end{tabular}

Composites with GF volume fractions between 38 and 61\% (cf. Table 1) were produced. Polished cross sections of the GF laminates were used to determine the void content via optical microscopy (VHX2000, Keyence, Japan). In order to highlight voids within the polished cross sections, a blue dye was applied during specimen preparation. For a better understanding of the heat transfer during the consolidation process, 5 thermocouples were embedded along the thickness of the composite. Specimens for mechanical testing were cut out of the unidirectional plates using a rotating diamond saw.

\subsection{Design of Experiments and Statistical Analysis}

For the systematic investigation on the process variables that influence the mechanical properties, designed experiments were used for PP/GF commingled yarns.

In order to study the interaction between the sizing content and the fiber volume content, a full factorial design was chosen. The sizing content was varied on six levels from 0 to $15 \mathrm{wt} \%$ whereas 3 levels from 41 to $60 \%$ fiber volume content were investigated. Based on these variables, composites were fabricated and the resulting mechanical properties where studied.

For the consolidation investigation, a Box-Behnken design resulted in 15 experiments according to three levels, and three factors was chosen. Besides the stepwise variation of the moulding pressure (0.75; 1.5 and $2.25 \mathrm{MPa})$, time $(7,14$ and $21 \mathrm{~min})$ and temperature $\left(195,210\right.$ and $\left.225^{\circ} \mathrm{C}\right)$ were changed and the resulting mechanical properties were used in order to determine consolidation quality. The statistical analysis of the experimental results was performed by analyzing the factorial design with statistics software (Statgraphics, Centurion, Miami, FL, USA). By creating regression equations, a model fit was obtained relating the results of the mechanical testing to main and secondary effects, respectively.

\subsection{Physical Characterization}

For mechanical testing, a universal test machine (Allround Line, Zwick Roell, Uim, Germany) with a contact strain extensometer (multiXtens, Zwick Roell, Uim, Germany) was utilized. Compression shear tests (CST) [5], tensile tests (ISO 527-5), transverse tensile tests (ISO 527-4), and 4 point bending tests (DIN ISO 14125) were performed.

Both pyrolysis at $700{ }^{\circ} \mathrm{C}$ in air and thermogravimetic analysis (Q500, TA Instruments, New Castle, DE, USA) were applied in order to determine the sizing content of the coated yarns. The crystallization and melting of the different matrix polymers was studied using differential scanning calorimetry (Q2000, TA Instruments, New Castle, DE, USA). The viscosity of the matrix and sizing polymers were 
determined using a rational rheometer (ARES G2, TA Instruments, New Castle, DE, USA). Prior to the investigations, all polymers were dried at $40{ }^{\circ} \mathrm{C}$ in a vacuum oven.

\section{Results and Discussion}

\subsection{Fundamental Aspects of Tailored Interphases in Commingled Yarns}

In contrast to thermosetting resins, thermoplastic filaments do not undergo chemical reactions during consolidation. Nevertheless, thermoplastics can be divided into polar polymers containing functional groups (e.g., PA6.6) and non-polar polymers. The non-polar PP is a typical example for a nonreactive polymer, but even the reactivity of PP can be increased by maleic anhydride grafting at compounding temperatures [7].

In order to further enhance adhesion between the glass fiber and matrix, coupling agents are applied via a sizing approach during the glass fiber spinning process. In general, sizings are mixtures of silane coupling agents, polymeric film formers, antistatic agents and lubricants [8]. Only silane coupling agents are necessary to promote adhesion between the glass fiber surface and the matrix. In detail, the silanol groups can form either hydrogen or covalent bonds to the glass fiber and the organofunctional groups can react with the matrix polymer during processing. Other ingredients are added to the sizing in order to achieve additional properties such as fiber protection against abrasion, strand integrity, fiber wet-out, lubrication and anti-static which are necessary for handling and processing.

Figure 2 illustrates the principle influence of PP grafting and sizing components on the transverse tensile strength of the composites. The laminate strength is up to 3 times higher for the MA-g-PP versus the PP matrix. This seems reasonable since the chemical reactivity is increased by the functional maleic anhydride groups at the end of the polymer chain. Nevertheless, the sizing does play an important role on the strength properties in both matrix systems.

Only a mixture of silane and MA-g-PP film former (sizing formulation consists of $1 \mathrm{wt} \%$ silane and $10 \mathrm{wt} \% \mathrm{MA}-\mathrm{g}$-PP film former) results in reasonable strength properties around 7.5 $\mathrm{MPa}$, whereas pure film former and pure silane provide strength levels below 2.5 MPa. The performance of each sizing can be explained by the chemical nature. The mixture of silane and film former can form a covalent bond to the glass fiber surface and to the functional group of the film former via the silane. The film former then cocrystallizes via physical entanglements with the molecular chains of the PP matrix. Thus, stress transfer from the matrix into the fiber is possible. The pure silane sizing can only form bonds with the glass fiber surface. Due to the absence of functional groups within the molecular chains of the matrix, the organo functional group of the silane is missing its counterpart, resulting in poor stress transfer. Vice versa, a pure film former sizing can form entanglements with the matrix but does not form bonds to the glass fiber surface, resulting in poor transverse strength as well. Quite interestingly, glass fibers sized only with deionized (DI) water show increased strain to failure levels of up to $10 \%$ at low strength levels, although no bonds are formed between the glass fiber and the matrix. One explanation may be that only the matrix Poisson contraction is hindered due to the glass fibers.

The same sizings perform differently in a MA-g-PP matrix. Pure film former and deionized water result in low strength levels, as expected. In contrast to the previous results, the silane sizing shows the highest strength and strain to failure results. This can be explained by the covalent bonds which are formed between the glass fiber surface and the grafted matrix molecular chains via the silane. The sizing containing a mixture of MA-g-PP film former and silane shows a lower strength and strain to failure in comparison to the pure silane sizing. It is likely that the silane will form covalent bonds with the glass fiber surface, whereas the organo functional complex can either react with the functional groups of the film former, which then form entanglements with the matrix polymer, or directly reacts with the functional groups of the matrix polymer. 

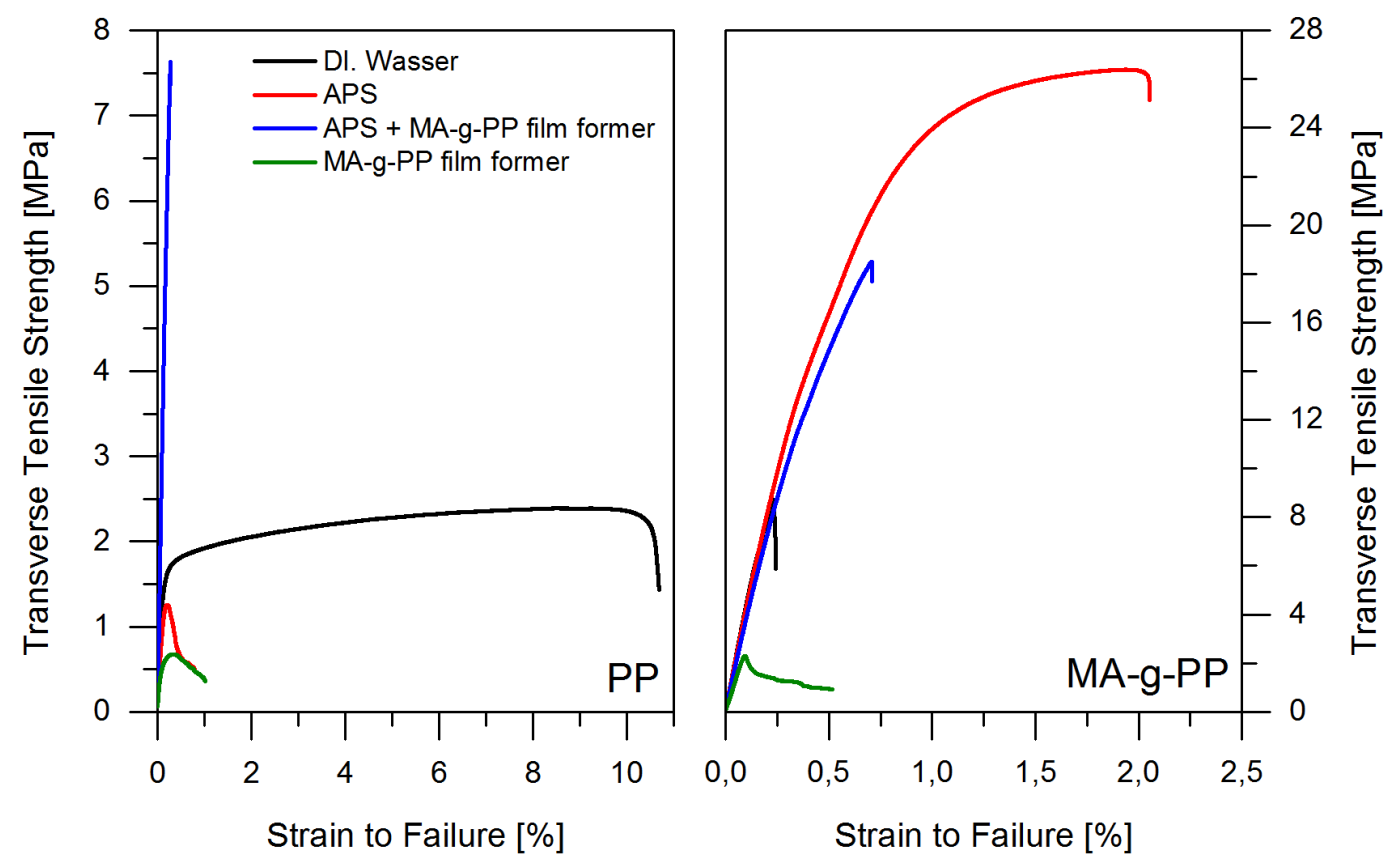

Figure 2. Influence of the matrix grafting (polypropylene (PP) un-grafted, left, MA-g-PP, right) and the sizing components ( $1 \mathrm{wt} \%$ silane and $10 \mathrm{wt} \% \mathrm{MA}-\mathrm{g}-\mathrm{PP}$ film former) on the mechanical performance of unidirectional GF/PP composites having a fiber volume content of $50 \%$.

Although the pure silane sizing shows the best mechanical results, it cannot be used in real processing, as previously mentioned. Therefore, the purpose of the following investigations was to determine how the performance of a film former/silane mixture is influenced by its ingredients. The commercially available film formers do not only consist of a MA-g-PP, but also contain surfactants and plasticizers. Figure 3A shows the influence of the molecular weight on the transverse tensile strength. The molecular weight affects the amount of entanglements which each chain forms with other chains. Higher weights result in more entanglements, thus achieving higher tensile strength properties [18]. The lowest molecular weight film former shows the lowest strength. The strength can be increased by increasing the molecular weight but remains unaffected as soon as a reasonable molecular weight is applied. Besides the molecular weight, the surfactant and the plasticizer can have an influence on the performance of a composite. Figure 3B shows the influence of an additional surfactant and plasticizer within a film former in comparison to a reference one. The purpose of the surfactant is to stabilize the MA-g-PP within the film former emulsion, whereas the plasticizer facilitates the emulsification process [19]. From a manufacturing point of view, it is therefore desirable to apply these substances in excess. Nevertheless, both substances are likely to reduce the strength properties of the composites. As it is shown in Figure 3B, a $10 \mathrm{wt} \%$ increase of surfactant content (red) in comparison to the reference film former yields no significant change in the strength properties. On the other hand, the same increase of plasticizer content results in a significant reduction of the strength.

As highlighted in Figure 4A, besides the surfactant level, it is also the surfactant charge which affects the transverse tensile strength. From a processing point of view, it is desirable to generate stable sizings with desired charge. It was possible for all surfactant charges to produce glass fibers in quantities necessary for composite manufacture. Only the nonionic surfactant tends to reduce the strength properties significantly, whereas cationic, anionic and nonionic/anionic mixtures result in nearly the same strength. 


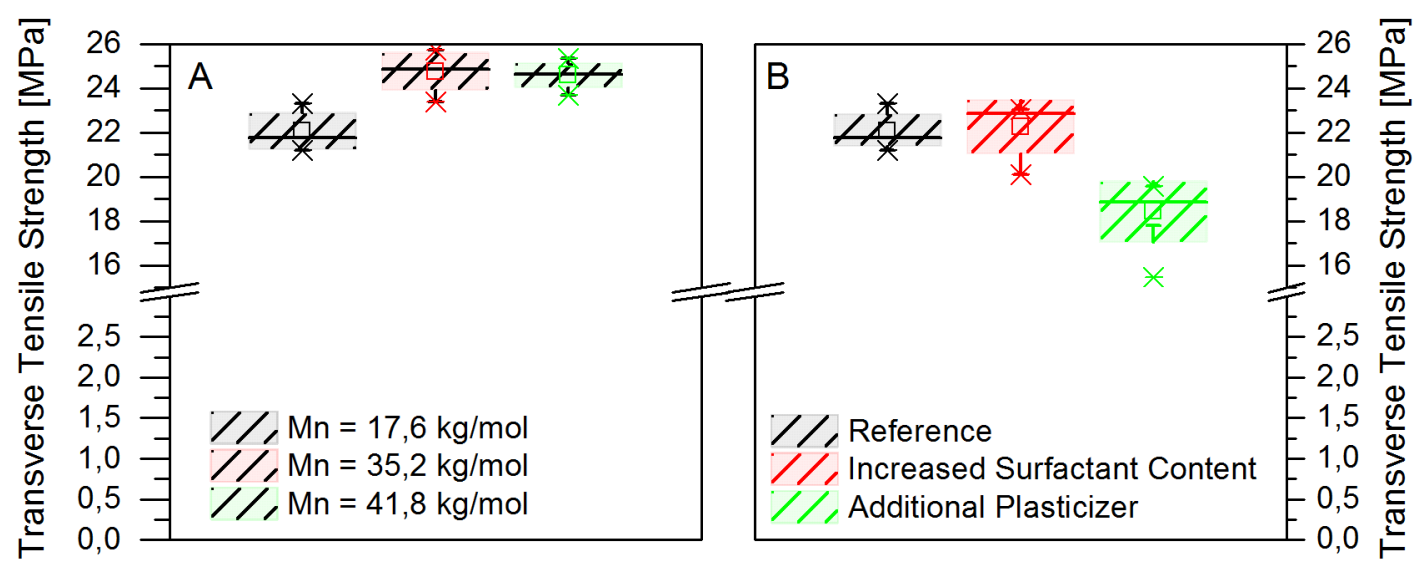

Figure 3. Influence of molecular weight of a MA-g-PP film former (A) and the components within a film former (B).

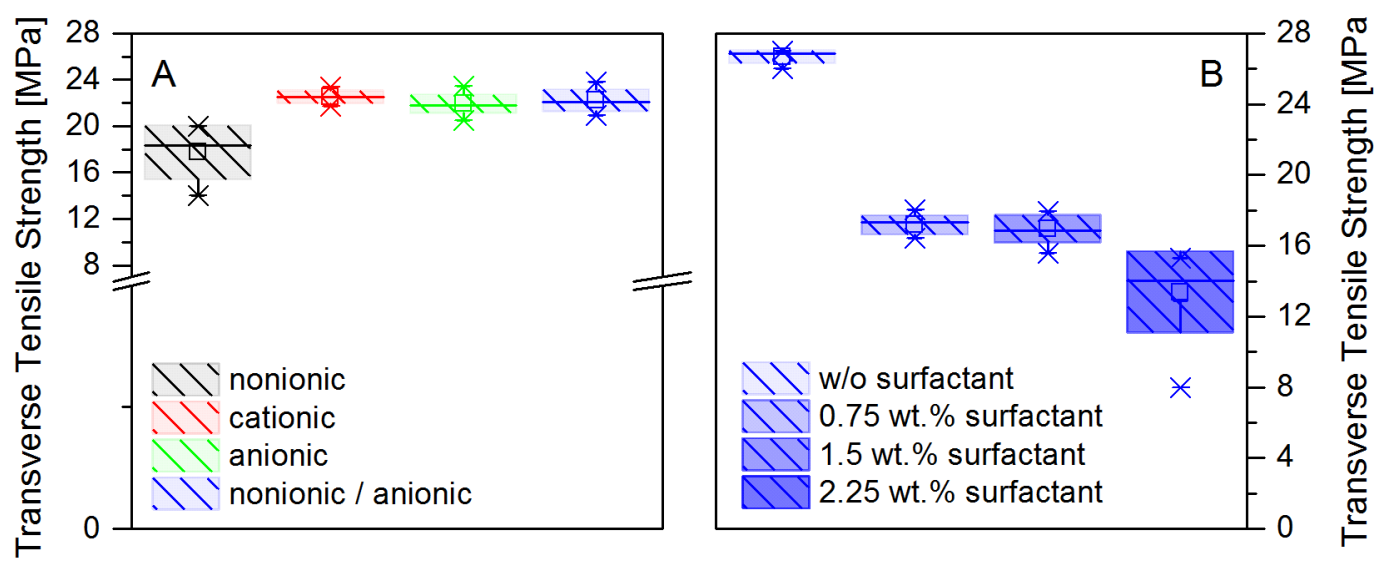

Figure 4. Influence of the surfactant charge (A) and the surfactant content on the glass fiber surface (B) on the mechanical properties of GF/PP composites.

In order to investigate the influence of the surfactant content (Figure 4B) independent of the MA-g-PP, mixtures of silane and surfactant were applied to the glass fiber surface. A very low content of $0.75 \mathrm{wt} \%$ surfactant already reduces the strength by almost one third, compared with the reference without surfactant. This highlights that surfactants cannot be beneficial for strength but have to be applied with care in order to achieve stable film former emulsions.

\subsection{Influence of Fiber Sizing Content on the Mechanical Performance}

In the previous chapter, the fundamental influence of the sizing chemistry on the strength of a unidirectional composite was discussed. Within the following paragraph, the influence of the amount of sizing which is applied during glass fiber spinning will be further examined. Thus, the sizing system always consists of the same APS silane at $1 \mathrm{wt} \%$ plus a MA-g-PP film former varying from 0 up to $15 \mathrm{wt} \%$ of the sizing. By increasing the weight percent of the film former, the solid content of the sizing is increased, which tends to enhance the viscosity of the sizing. Consequently, the fiber picks up more sizing when it passes the sizing applicator roll yielding to an increased sizing content and thus a thicker average sizing layer on the fiber. Besides the sizing content, the fiber volume content was systematically changed from 42 until $62 \mathrm{vol} \%$. The design of experiments was used for planning and analyzing the strength and stiffness results of the composite testing.

As the Pareto chart in Figure 5 shows, the film former has a significant influence on the strength. It tends to decrease the transverse tensile strength. The fiber volume content is not significantly 
changed from a statistical point of view. The coupling effect between both tends to be right on the edge of significance, indicated by the blue line in the chart. Quite surprisingly, it is not the fiber volume content which dominates the strength, but the sizing content. The principle reduction in strength due to the increased sizing level can be explained by the chemical nature of the film former. In contrast to the matrix PP, the film former consists of a significantly lower molecular weight PP. To a large extent, the physical properties, e.g., strength and stiffness, are influenced by the molecular weight. As a bulk material, the film former polymer is very brittle and has a low strength of about $7 \mathrm{MPa}$ and a strain to failure of only $4 \%$. In contrast, the matrix polymer shows intensive yielding and strength of about $25 \mathrm{MPa}$. Based on the increased strain concentrations for higher fiber volume contents [20], one would rather assume a waste reduction in strength for increased fiber levels.
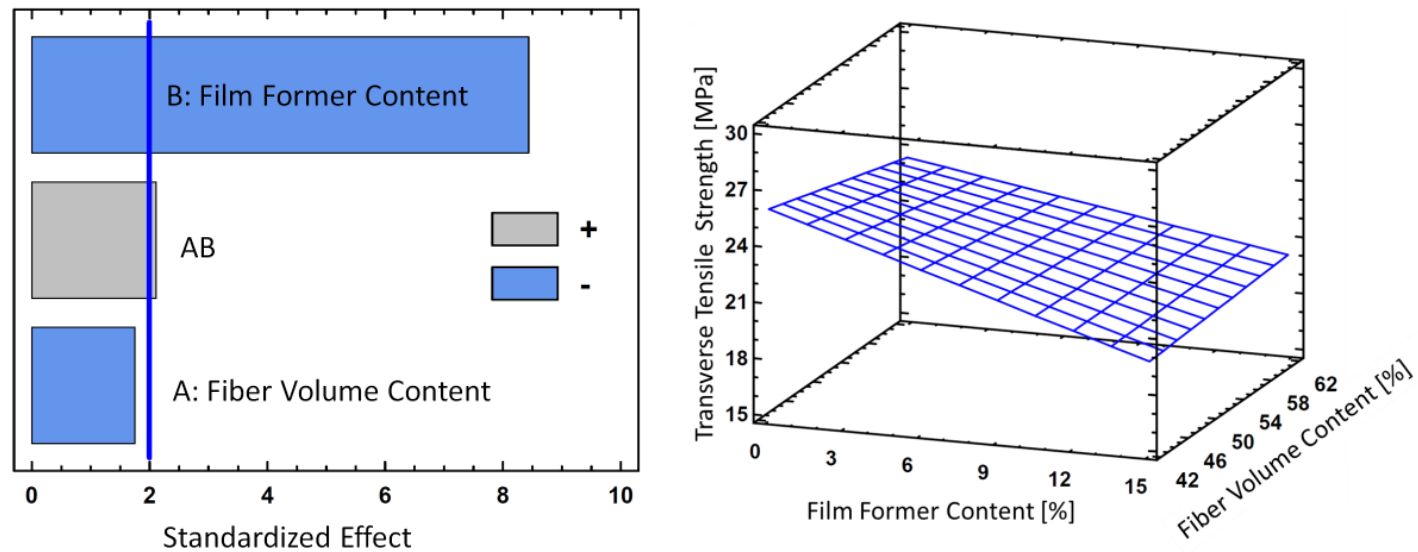

Figure 5. Pareto chart (left) and response surface plot (right) for the transverse tensile strength depending on the fiber volume content and the film former content.

In contrast to the strength results, Figure 6 shows that the fiber volume content has a major influence on the Young's modulus perpendicular to the direction of fibers. Increasing the fiber volume content results in increased Young's modulus, which corresponds to the well-established micromechanical models [21]. On the other hand, the film former has a detrimental influence on the modulus. Throughout all of the investigated film former levels, the modulus is significantly reduced. Although the Young's modulus of the bulk film former and the matrix polymer are only marginally different, within the fiber interphase the low molecular weight film former clearly reduces the overall stiffness of the composite.
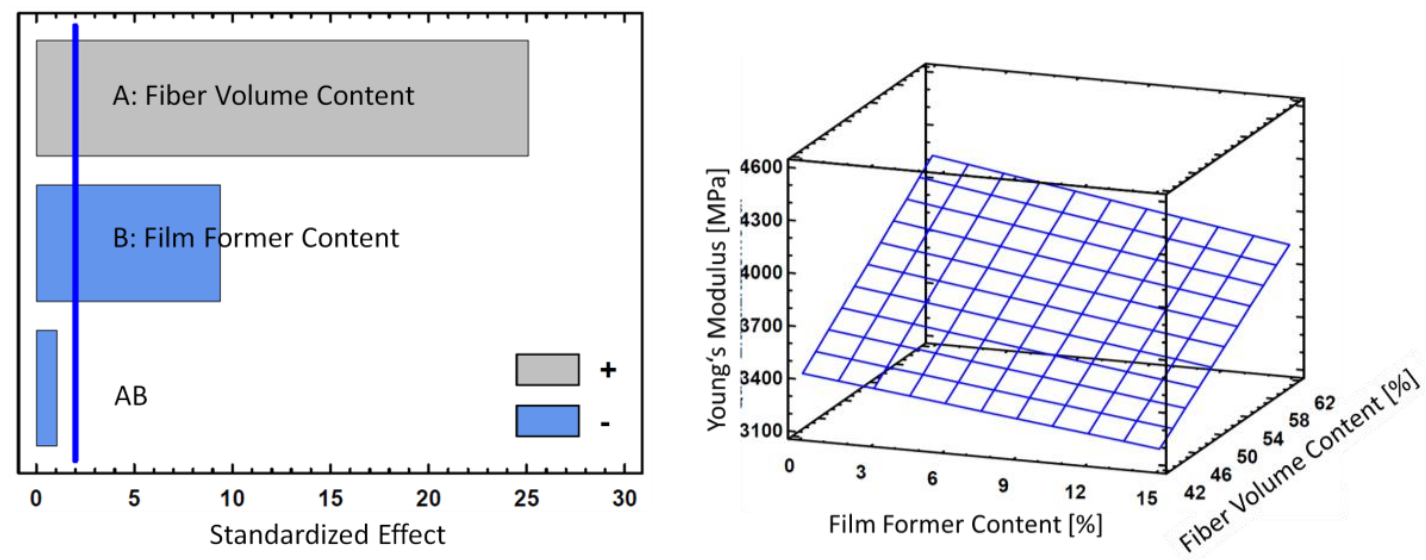

Figure 6. Pareto chart (left) and response surface plot (right) for the Young's modulus depending on the fiber volume content and the film former content. 


\subsection{Influence of Time, Temperature and Pressure During Consolidation on the Mechanical Performance}

The consolidation of continuous fiber-reinforced thermoplastics has been widely addressed in the literature [22-31]. It is well accepted that the impregnation during the consolidation consists of a macroscale and microscale impregnation. During the macroscale impregnation, molten matrix flows between fiber bundles, whereas during the microscale impregnation, the single fibers are infiltrated by the molten matrix, which is roughly considered by Darcy's law.

The aim of this chapter is to investigate the influence of the processing parameters on the transverse tensile strength using a Design of Experiments (DOE) approach. For a better understanding of the impregnation behavior and the void content, polished cross sections for each specimen were prepared. In order to monitor the heat transfer and the temperature distribution during the consolidation, each plate was equipped with thermocouples along the thickness.

Figure 7 demonstrates that, during the isothermal consolidation trials, the time and the temperature have a significant impact on the mechanical properties. This behavior correlates well with previous composite consolidation studies [28]. Besides these linear factors, a quadratic term of the time and an interaction between temperature and time are responsible for the reduction in strength. The influence of the pressure is much lower than all previously mentioned ones which can be attributed to the homogeneous fiber distribution level in the online commingled yarns and consequently short distances for the matrix to flow.

According to the literature [25], the void content tends to determine the mechanical performance of the composite. Figure 8 reports the evolution of the voids during different consolidation conditions. As expected by the results of the DOE, the void content decreases with increasing temperature and holding time, whereas the pressure only has a minor influence illustrated for the $14 \min 195{ }^{\circ} \mathrm{C}$ sample (Pressure 0.75 and $2.25 \mathrm{MPa}$ ). The temperature has a major impact on the consolidation quality, as expected. From $180^{\circ} \mathrm{C}$ consolidation temperature onwards, the void content can significantly be reduced, highlighted by the orange dotted line within the temperature graphs in Figure 8. The influence of the time on the mechanical performance can be clearly espaliered by a close look on the temperature distribution through the thickness along consolidation time. As soon as the heatable platen press reaches its pre-defined temperature level ( 0 min time, black line), the temperature distribution along the 48 plies of the composite is somehow different. The top plies near the press have already reached the defined temperature level, whereas the lowest plies are almost $100 \mathrm{~K}$ colder. The temperature difference between top and bottom becomes less with proceeding time. After 21 min (green line) it is almost in equilibrium. Since the temperature is introduced via the top plie, void content is not homogeneously distributed through the thickness. Only the bottom areas which have not reached temperature levels above $180^{\circ} \mathrm{C}$ along the holding time tend to have voids.
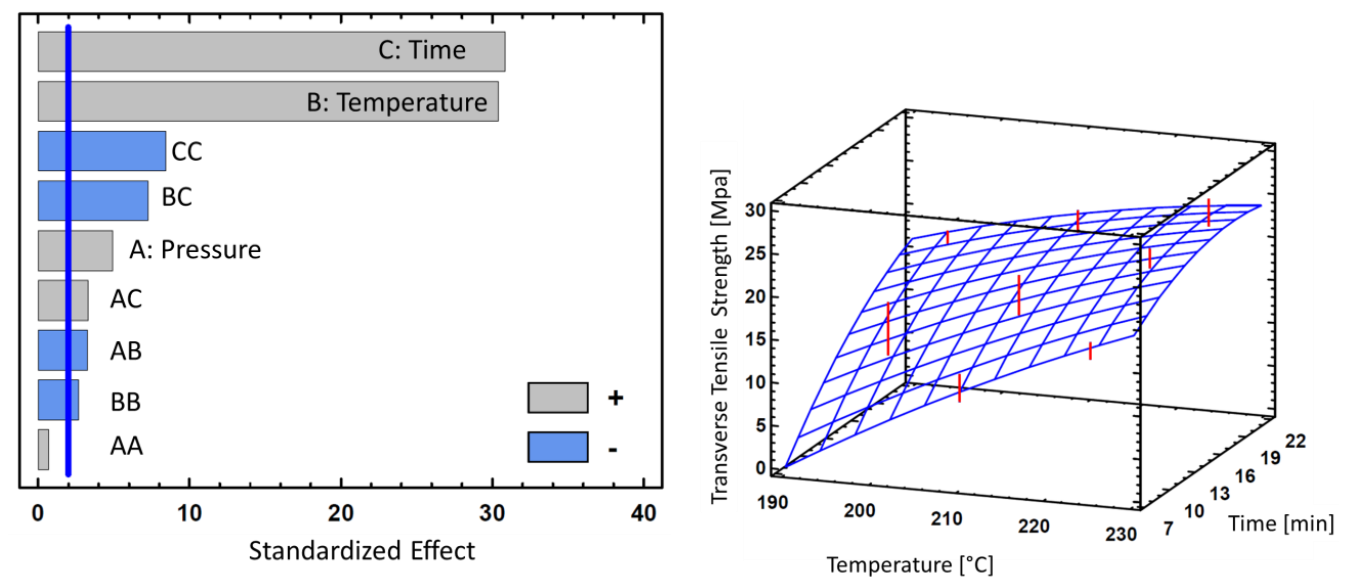

Figure 7. Pareto chart (left) and response surface plot (right) for the transverse tensile strength depending on the processing parameters, time and temperature, for a constant pressure of $1.5 \mathrm{MPa}$. 

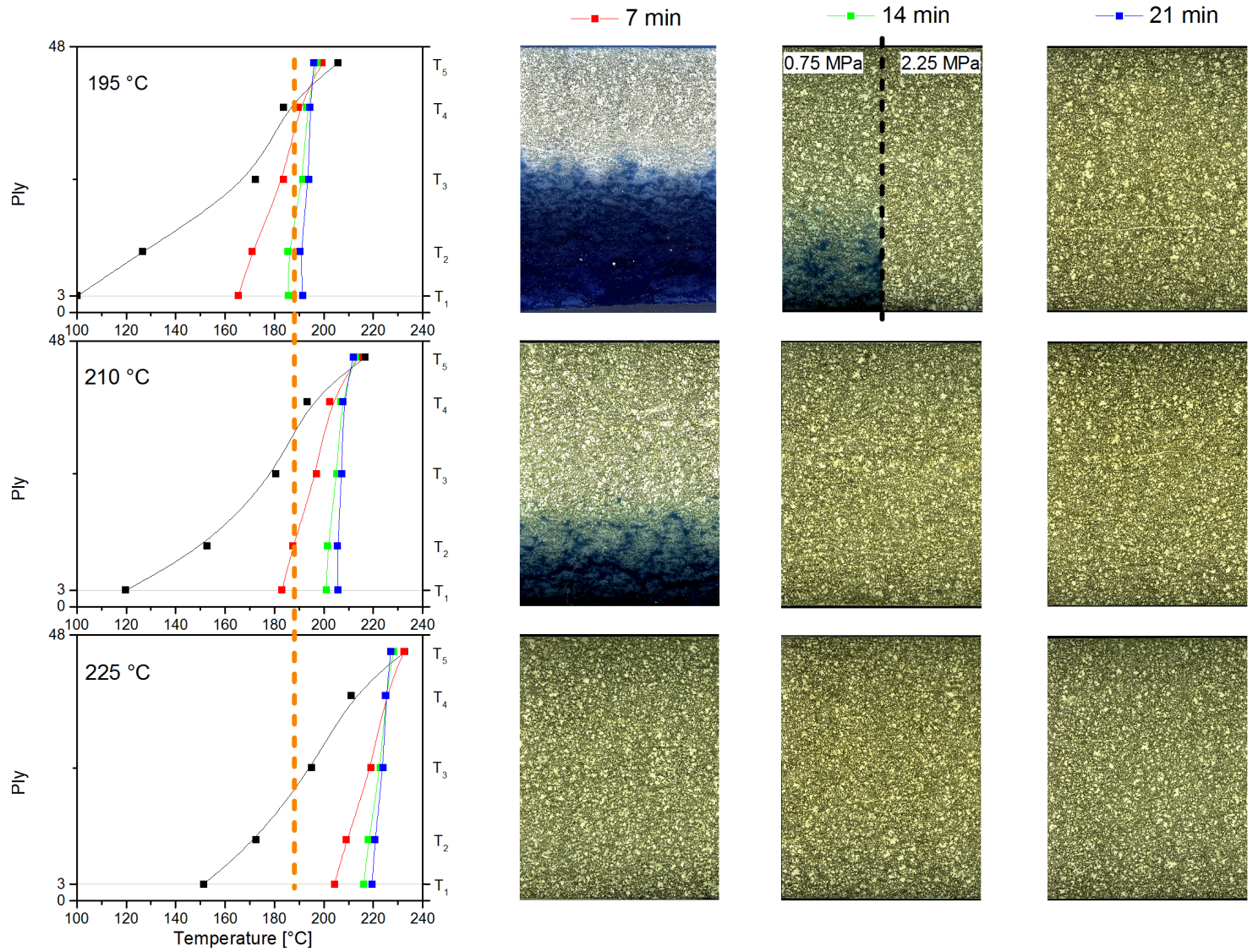

Figure 8. (Left) Temperature distribution through the thickness for 195,210 and $225^{\circ} \mathrm{C}$ isothermal temperature at the beginning of the isothermal holding (black), after $7 \mathrm{~min}$ (red), after 14 min (green) and after $21 \mathrm{~min}$ (blue); (right) Corresponding polished cross section to the temperature and time with voids highlighted in blue (for a constant pressure of $0.75 \mathrm{MPa}$ despite the middle top one). The orange dotted line highlights the temperature from where on void free composites are generated.

It is still open for discussion what really happens in the temperature region until $180^{\circ} \mathrm{C}$. The glass transition temperature of the PP matrix is somewhat in the region of $-5^{\circ} \mathrm{C}$. Melting of the crystalline areas occurs between 155 and $170{ }^{\circ} \mathrm{C}$. As a consequence, the viscosity of the PP drops within the melting area by almost 3 decades, as reported in Figure 9. The drop in viscosity goes along with different distinctive events which can be observed in a polished cross section of a specimen $\left(195{ }^{\circ} \mathrm{C}\right.$, $7 \mathrm{~min}, 0.75 \mathrm{MPa}$, Figure 8 right) containing perfect consolidated areas on the top and almost pristine commingled yarn areas with no sign of consolidation on the bottom. At temperatures below $165^{\circ} \mathrm{C}$, the circular-shaped polymer filaments deform plastically changing their shape, but voids with the polymer bundles are still visible. Between 165 and $180^{\circ} \mathrm{C}$, the polymer filaments sinter, intrabundle voids are removed and macroscale impregnated areas become visible. Above $180^{\circ} \mathrm{C}$, the glass fibers are wetted out by matrix which flows from the resin-rich pools into the glass fiber bundles. These findings go along with more recent literature results which try to explain commingled yarn consolidation via a sintering approach [32] rather than by Darcy's law.

Nevertheless, the void content cannot be the only reason for an increased mechanical performance throughout the consolidation trials. Especially composites which do not show any sign of voids (e.g., above $195{ }^{\circ} \mathrm{C} / 14 \mathrm{~min}$ or $210^{\circ} \mathrm{C} / 7 \mathrm{~min}$ ) display differences in the transverse tensile strength, as presented in the response surface plot in Figure 7. Since the heating and cooling rates were not changed throughout all experiments, these changes cannot be directly attributed to any difference in the melting or crystallization state during consolidation. Although the consolidation on the macroand microscale appears to be void-free, it is still to be questioned what happens on the nanoscale 
near the glass fiber surface. The important influence of the glass fiber interphase on the mechanical performance has been already addressed in the two previous chapters. An increase in temperature always goes along with increased molecule mobility, which facilitates the interpenetration of the matrix into the sizing network and vice versa. Furthermore, the probability that each functional group can react with a counterpart is also increased. It is likely that all these effects tend to have a positive impact on the mechanical performance.
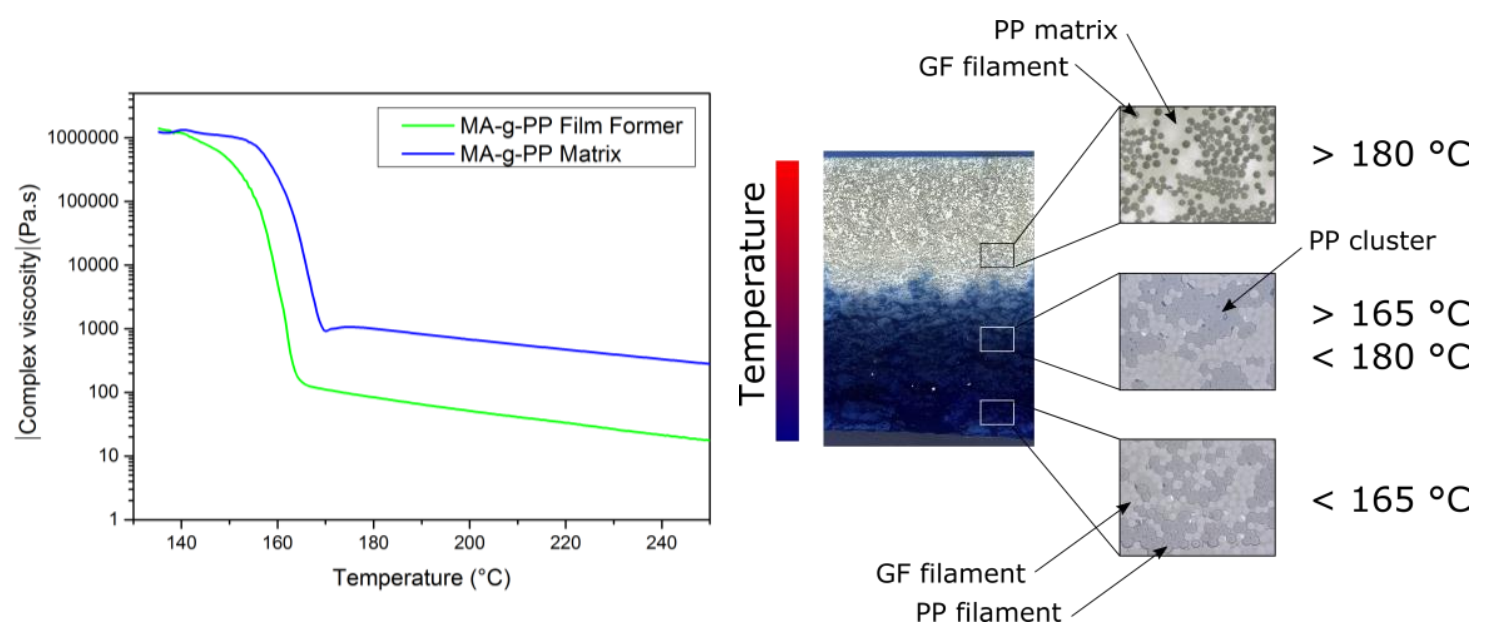

Figure 9. (Left) Viscosity-temperature plot for matrix and film former PP; (right) a closer look on the consolidation behavior in commingled yarn composites: Plastic deformation of PP filaments, sintering and intrabundle void reduction followed by polymer flow into the glass fiber bundles.

\subsection{Effects of the Fiber Volume Content in GF/PP Composites on the Mechanical Properties}

The fiber volume content of online hybrid yarns was varied by the spinning pump settings during the polymer yarn spinning process within the region of about 40 to $60 \mathrm{vol} \%$. In order to manufacture specimens for mechanical testing, unidirectional composites were made based on filament winding of hybrid yarns followed by isothermal consolidation at $225^{\circ} \mathrm{C}$ using a heatable platen press at a pressure of $1.5 \mathrm{MPa}$ for $21 \mathrm{~min}$ throughout the variation of the fiber volume content. The fiber/matrix distribution homogeneity was very high and was not affected by the fiber volume variation. Figure 10 shows exemplarily polished cross sections of unidirectional GF/PP composites containing $42 \mathrm{vol} \%$ and $60 \mathrm{vol} \%$ glass fibers, respectively. Figure 11 reveals that it is possible to tailor Young's modulus and to optimize the fiber dominated mechanical strength properties of the unidirectional composites in longitudinal and transverse fiber direction with the fiber volume content. Both the Young's moduli in $0^{\circ}$ and $90^{\circ}$ fiber direction increased linearly determined after tensile and flexural loading as a function of the fiber volume content (Figure 11a-c). Simultaneously, the strain to failure values decreased. This is also due to the nearly linear elastic behavior up to the failure which is also displayed by the stress-strain curves (Figure 12). In transverse fiber direction, the tensile strength and compression shear strength slightly decrease with enhancing fiber volume content, which is due to the stress concentration and limited matrix yielding within the interphase region due to decreased matrix paths between the single reinforcement fibers (Figure 11b,d). The Charpy impact toughness is also slightly deteriorated with increasing fiber volume content due to limited matrix yielding (Figure 11d). 

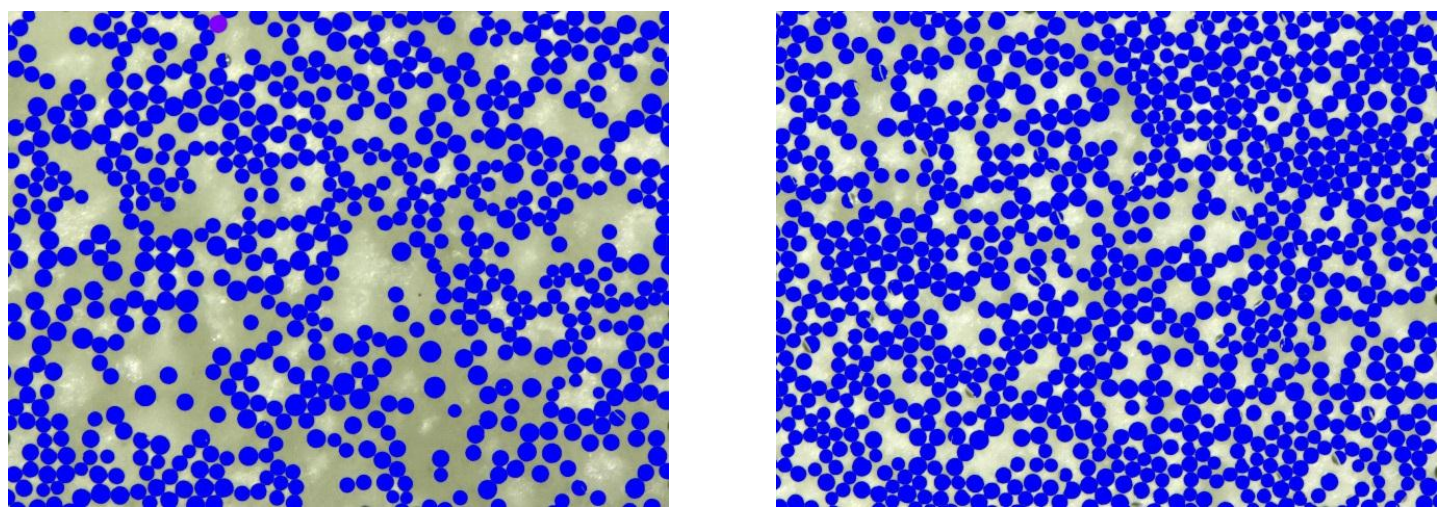

Figure 10. Polished cross sections of unidirectional GF/PP composites containing $42 \mathrm{vol} \%$ (left) and $60 \mathrm{vol} \%$ (right) glass fibers. The glass fibers are highlighted in blue color.

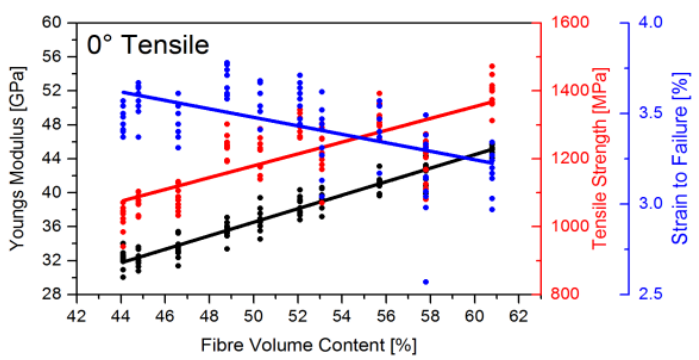

(a)

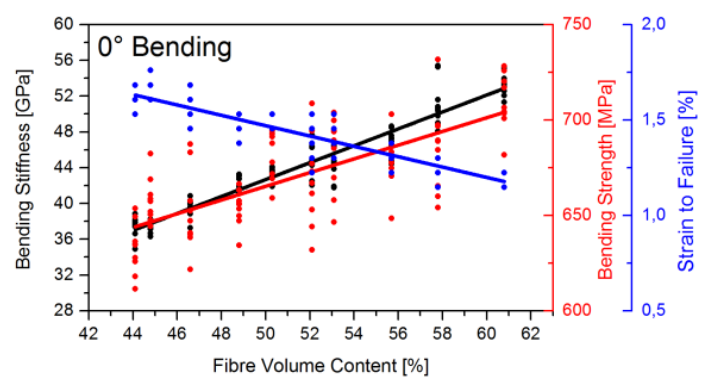

(c)

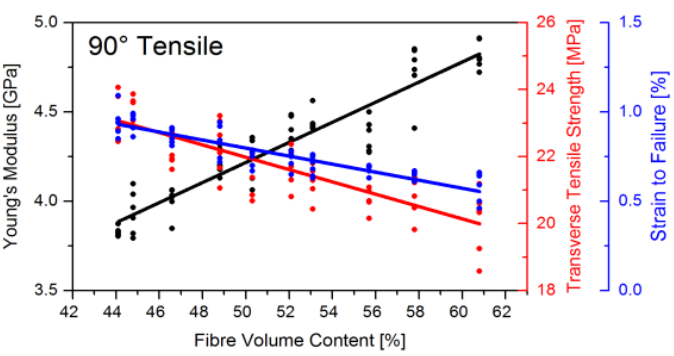

(b)

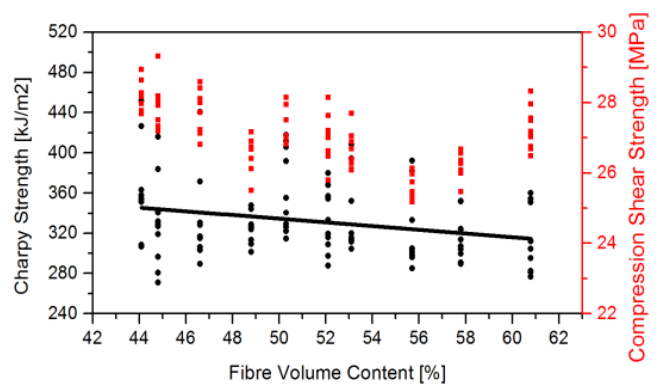

(d)

Figure 11. Young's modulus, tensile strength, bending stiffness, bending strength and strain to failure of GF/PP composites depending on the fiber volume content. (a): $0^{\circ}$ tensile test; (b): $90^{\circ}$ tensile test; (c): $0^{\circ}$ bending test; (d): Charpy impact test and compression shear test.

\subsection{Effects of Sizings in GF/PLA and GF/PA6.6 Composites on Their Mechanical Performance}

For the GF/PLA composites containing a constant silane content of $1 \mathrm{wt} \%$ and constant film former content of $10 \mathrm{wt} \%$ in the sizing formulations, the epoxy film former (S1) based sizing, as well as the chitosan-based sizing (S3), showed a significant increase of interphase strength being reflected in improved mechanical properties of the composites transverse to fiber direction, such as transverse tensile strength and compression shear strength (Figure 12a). The especially biodegradable chitosan-based sizing S3 will be selected for further component design and application. The stress-strain-curves of GF/PLA composites based on sized fibers $\mathrm{S} 0$ with bioresorbable commercial finish and S2 with polyurethane film former indicated significantly lower maximum values for stress and strain, which reveal poor stress transfer of the composites interphases. The average stress-strain curves (Figure 13) confirm the different adhesion strength leading to different mechanical performance of GF/PLA composites. 
For the GF/PA6.6 composites, the variations in terms of transverse tensile strength and compression shear strength (Figure 12b) are even more pronounced, beginning from $3 \mathrm{MPa}$ (V5) and ending at $73 \mathrm{MPa}(\mathrm{V7})$. These findings are also reflected by the stress-strain curves (not shown here), which indicated a very early failure for poor interphase strength when polyurethane/polyacrylate film former (V3) was applied, whereas both strength and strain increased significantly with improved interfacial interaction. Unexpectedly, GF with $1 \mathrm{wt} \%$ 3-Aminopropyl-triethoxysilane and without film former (V7) revealed the best transverse tensile strength. It indicates that all film formers (constant $10 \mathrm{wt} \%$ in sizing formulations) used in the sizing formulations decreased tensile strength to a certain extent and did not contribute to improved toughness. Further research is necessary to reveal the mechanisms influenced by local nanoscale interphase properties.

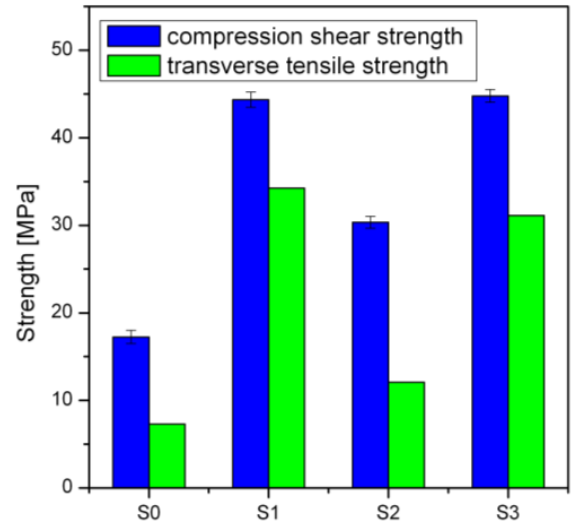

(a)

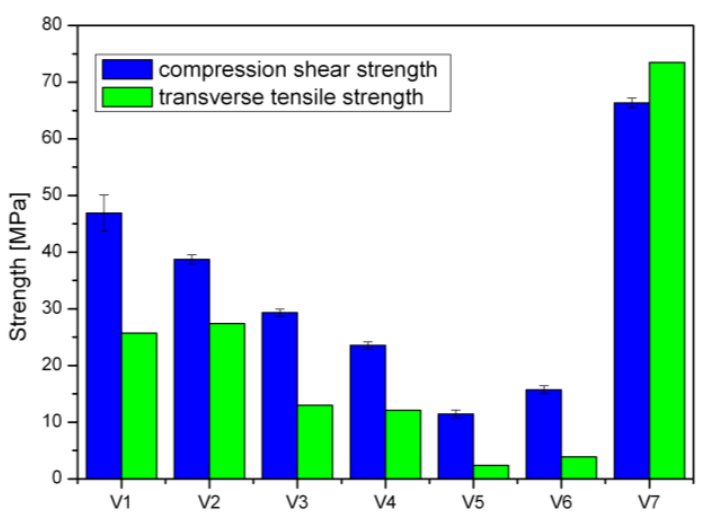

(b)

Figure 12. Mechanical performance for GF/polylactic acid (PLA) composites with different sizings S0 to S3 (a) and GF/PA6.6 composites with different sizings V1 to V7 (b).

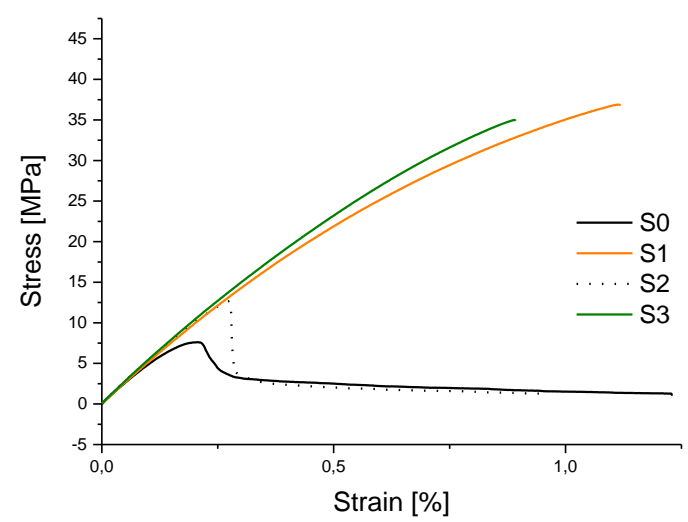

Figure 13. Average stress-strain curves for GF/PLA composites with different sizings S0 to S3.

\section{Conclusions}

Glass fiber commingled yarns with different matrix polymers and sizing chemistry were investigated in terms of mechanical performance and consolidation behavior upon mechanical loading. Based on the results, the influence of the sizing, in particular the variation of the sizing components and weight contents in polypropylene/glass fiber composites had a significant influence on the mechanical performance of the later composites. The influence of the sizing was also visible throughout the variation of the fiber volume content and the matrix polymer, emphasizing that tailored sizing should be carefully chosen in order to achieve excellent performance in composites. 
For polypropylene matrices, only a mixture of silane and MA-g-PP film former results in reasonable strength properties. The mixture of silane and film former can build a covalent bond to the glass fiber surface and to the functional group of the film former via the silane. The film former can cocrystallize via physical entanglements with the chain of the PP-matrix. Due to the absence of functional groups within the polymer chains of the matrix, the organo functional group of the silane is missing its counterpart, resulting in poor adhesion strength. Vice versa, a pure film former sizing can form entanglements with the matrix but does not form bonds to the glass fiber surface. The pure silane sizing shows the highest strength and strain to failure results within the MA-g-PP matrix, because covalent bonds are formed between the glass fiber surface and the grafted matrix chains via the silane. The sizing containing a mixture of MA-g-PP film former and silane shows a somewhat lower strength and strain to failure compared to the pure silane sizing. The same behavior was detected for PA6.6 matrices and PLA matrices. Although the pure silane sizing shows the best mechanical results, it cannot be used in continuous real fiber processing because of poor strand integrity. Therefore, detailed investigation on film former chemistry compatible with the polymer matrix and the influence of additives is needed to reveal the interphase properties in nanoscale. Surprisingly, for PLA matrices, sizings consisting of silane and chitosan film formers show the best performance in composites.

Consolidation was experimentally investigated in-depth and void-free composites could be achieved by choosing a suitable combination of temperature and time. The influence of the sizing had clearly been identified, therefore it will be reasonable to employ multifunctional effects such as a conductive CNT network additionally via a sizing onto the heavily strained interphase region of the composites. Taking advance of the electrical resistance change upon mechanical loading and ultimate failure, structural health monitoring can be achieved.

Acknowledgments: The authors express their gratitude towards the Deutsche Forschungsgemeinschaft (DFG) for financial support within the Collaborative Research Centre 639 (SFB) project A1.

Author Contributions: Niclas Wiegand and Edith Mäder conceived and designed the experiments; Niclas Wiegand performed the experiments. Niclas Wiegand and Edith Mäder analyzed and discussed the data and wrote the paper.

Conflicts of Interest: The authors declare no conflict of interest.

\section{References}

1. Mäder, E.; Rausch, J.; Schmidt, N. Commingled yarns-Processing aspects and tailored surfaces of polypropylene/glass composites. Compos. Part A 2008, 39, 612-623. [CrossRef]

2. Mäder, E.; Moos, E.; Karger-Kocsis, J. Role of film formers in glass fibre reinforced polypropylene-New insights and relation to mechanical properties. Compos. Part A 2001, 32, 631-639. [CrossRef]

3. Rausch, J.; Mäder, E. Health monitoring in continuous glass fibre reinforced thermoplastics: Manufacturing and application of interphase sensors based on carbon nanotubes. Compos. Sci. Technol. 2010, 70, 1589-1596. [CrossRef]

4. Rausch, J.; Mäder, E. Health monitoring in continuous glass fibre reinforced thermoplastics: Tailored sensitivity and cyclic loading of CNT-based interphase sensors. Compos. Sci. Technol. 2010, 70, 2023-2030. [CrossRef]

5. Rausch, J.; Mäder, E. Carbon nanotube coated glass fibres for interphase health monitoring in textile composites. Mater. Technol. 2011, 26, 153-158. [CrossRef]

6. Lehtonen, T.; Tuominen, J.; Rausch, J.; Mäder, E. Biodegradable continuous fibre reinforced composites based on hybrid yarns. In Proceedings of the ICCM 18, Jeju, South Korea, 21-26 August 2011.

7. Russell, K. Free radical graft polymerization and copolymerization at higher temperatures. Prog. Polym. Sci. 2002, 27, 1007-1038. [CrossRef]

8. Plueddemann, E.P. Silane Coupling Agents; Springer Science + Business Media: New York, NY, USA, 1991; pp. $29-45$.

9. Kim, J.-K.; Mai, Y.-W. High Strength, High Fracture Toughness Fibre Composites with Interface Control-A Review. Compos. Sci. Technol. 1991, 41, 333-378. [CrossRef]

10. Pukanszky, B. Interfaces and Interphases in Multicomponent Materials: Past, Present, Future. Eur. Polym. J. 2005, 41, 645-662. [CrossRef] 
11. Ishida, H. A Review of Recent Progress in the Studies of Molecular and Microstructure of coupling Agents and Their Functions in Composites. Polym. Compos. 1984, 5, 101-123. [CrossRef]

12. Zhuang, R.-C.; Burghardt, T.; Mäder, E. Study on Interfacial Adhesion Strength of Single Glass Fibre/Polypropylene Model Composites by Altering the Nature of the Surface of Sized Glass Fibres. Compos. Sci. Technol. 2010, 70, 1523-1529. [CrossRef]

13. Fiedler, B.; Gojny, F.H.; Wichmann, M.H.G.; Bauhofer, W.; Schulte, K. Can Carbon Nanotubes Be Used to Sense Damage in Composites? Ann. Chim.-Sci. Mater. 2004, 2, 981-994. [CrossRef]

14. Thostenson, E.T.; Chou, T.W. Carbon Nanotube Networks: Sensing of Distributed Strain and Damage for Life Prediction and self healing. Adv. Mater. 2006, 18, 2837-2841. [CrossRef]

15. Thostenson, E.T.; Chou, T.W. Real-Time In Situ Sensing of Damage Evolution in Advanced Fiber Composites Using Carbon Nanotube Networks. Nanotechnology 2008, 19, 215713. [CrossRef] [PubMed]

16. Wiegand, N.; Mäder, E. Multifunctional Interphases: Percolation Behavior, Interphase Modification, and Electro-Mechanical Response of Carbon Nanotubes in Glass Fiber Polypropylene Composites. Adv. Eng. Mater. 2016, 18, 376-384. [CrossRef]

17. Schilling, N.; Wiegand, N.; Klotzbach, U. Laser Assisted Electrical Contacting in Multifunctional GF/PP Composites. Mater. Sci. Forum. 2015, 825-826, 541-547. [CrossRef]

18. Stern, C.; Frick, A.R.; Weickert, G.; Weickert, G.; Micher, G.H.; Henning, S. Processing, Morphology, and Mechanical Properties of Liquid Pool Polypropylene with Different Molecular Weights. Macromol. Mater. Eng. 2005, 290, 621-635. [CrossRef]

19. Kern Sears, J.; Darby, J.R. The Technology of Plasticicizers; Wiley: New York, NY, USA, 1982.

20. Schürmann, H. Konstruieren Mit Faser-Kunststoff-Verbunden; Springer: Berlin, Germany, 2007; pp. 393-440.

21. Hull, D. An Introduction to Composite Materials; Press Syndicate of the University of Cambridge: New York, NY, USA, 1996; pp. 60-77.

22. Van West, B.P.; Pipes, R.B.; Advani, S.G. The consolidation of commingled thermoplastic fabrics. Polym. Compos. 1991, 12, 417-427. [CrossRef]

23. Ye, L.; Friedrich, K.; Kästel, J.; Mai, Y.-W. Consolidation of unidirectional CF/PEEK composites from commingled yarn prepreg. Compos. Sci. Technol. 1995, 54, 349-358. [CrossRef]

24. Ye, L.; Friedrich, K.; Kästel, J. Consolidation of GF/PP commingled yarn composites. Appl. Compos. Mater. 1995, 1, 415-429. [CrossRef]

25. Svensson, N.; Shishoo, R.; Gilchrist, M. Manufacturing of Thermoplastic Composites from Commingled Yarns-A Review. J. Thermoplast. Compos. Mater. 1998, 11, 22-56. [CrossRef]

26. Ma, Y.; Shishoo, R. The Influences of Processing Parameters on the Fiber Distribution and Matrix Flow of Unidirectional Glass Fiber/Polyethylene Terephthalate (GF/PET) Commingled Yarns. J. Thermoplast. Compos. Mater. 1999, 12, 424-442. [CrossRef]

27. Bernhardsson, J.; Shishoo, R. Compression Molding of Warp-Knitted PET/GF Based Composites: Influence of Forming Temperature on Consolidation Quality and Impact Properties. J. Thermoplast. Compos. Mater. 2000, 13, 326-341. [CrossRef]

28. Bernhardsson, J.; Shishoo, R. Effect of processing parameters on consolidation quality of GF/PP commingled yarn based composites. J. Thermoplast. Compos. Mater. 2000, 13, 292-313. [CrossRef]

29. Wakeman, M.D.; Rudd, C.D.; Cain, T.A.; Brooks, R.; Long, A.C. Compression moulding of glass and polypropylene composites for optimised macro-and micro-mechanical properties. 4: Technology demonstrator-a door cassette structure. Compos. Sci. Technol. 2000, 60, 1901-1918. [CrossRef]

30. Thomann, U.I.; Sauter, M.; Ermanni, P. A combined impregnation and heat transfer model for stamp forming of unconsolidated commingled yarn preforms. Compos. Sci. Technol. 2004, 64, 1637-1651. [CrossRef]

31. Thomanny, U.I.; Ermanni, P. The Influence of Yarn Structure and Processing Conditions on the Laminate Quality of Stamp formed Carbon and Thermoplastic Polymer Fiber Commingled Yarns. J. Thermoplast. Compos. Mater. 2004, 17, 259-283. [CrossRef]

32. Greco, A.; Strafella, A.; Tegola, C.L.; Maffezzoli, A. Assessment of the relevance of sintering in thermoplastic commingled yarn consolidation. Polym. Compos. 2011, 32, 657-664. [CrossRef]

(C) 2017 by the authors. Licensee MDPI, Basel, Switzerland. This article is an open access article distributed under the terms and conditions of the Creative Commons Attribution (CC BY) license (http:/ / creativecommons.org/licenses/by/4.0/). 